pathogens, there are, surprisingly, no legal requirements for handling materials potentially infectious for man; this despite the fact that these may present a more frequent and more alarming hazard.

Clinical laboratory staff may often include "school leavers" who, as juveniles, are legally barred from contact with radioactive materials. They are, nevertheless, often the people who first or most frequently handle samples sent to the laboratory. Almost the only official guidance for dealing with infective samples is contained in a report from the Public Health Laboratory Service which was recently revised and reissued by the Department of Health and Social Security (1970). This is solely concerned with specimens from tuberculous patients and has not legal authority; indeed, during 1970 less than one-third of the regional hospital laboratories handling tuberculous samples observed the recommended standard of protection for technical staff, and $13 \%$ of the laboratories did not even offer immunization against the disease (Guardian, 23 January 1971).

Many clinical laboratories already receive over 200 blood samples each working day, and as it has been found that, in Britain, about 1 in 200 blood donors is a symptomless carrier of infectious hepatitis (Hartney, 1970), several infected samples can be expected each week from apparently healthy persons or from patients with "non-hepatic" disorders. In addition, with the increasing incidence of septicaemia (Altemeier, 1967) a higher proportion of samples containing pathogenic bacteria can be expected. As greater use is made of international air travel, unexpected exotic diseases, imported unwittingly, will extend yet further the hazards to which laboratory staff are exposed.

The problem of infectious hepatitis among ciinical laboratory staff has led to the formulation of proposals by pathologists to minimize the risks, but those seen by us have concentrated on contagious risks, with but little appreciation either of the ease with which aerosols are generated or of their importance in laboratory-acquired infections. The assumption that aerosols of infectious hepatitis virus are innocuous, always dangerous, is now untenable since the report of Almeida et al. (1971), which strongly suggests that airborne transmission of infectious hepatitis can occur.

The only safe approach to handling samples which may contain unknown amounts of unknown pathogens is to regard them all as potentially lethal and, therefore, to carry out investigations on them with maximum safety precautions. In principle, this would require that an effective barrier be maintained be- tween specimens and staff at all times. This is unlikely to be accepted at present on the grounds of cost and inconvenience, although analogous precautions are used in various sectors of the electronics industry (Doxie and Ullom, 1967). Nevertheless, all clinical laboratory procedures of especial risk, such as opening specimen containers, centrifuging, and pipetting, should be isolated in properly maintained ventilated enclosures of suitable design (see, for example, Evans, Harris-Smith, and Stratton, 1972). Some of the dangers associated with bloodtaking (Table I) could be obviated by wider use of syringe-less methods, such as those using evacuated containers, although in their present form these are not entirely satisfactory. There can certainly be no justification for continuing to examine, in the open laboratory, specimens from known or suspected cases of infectious hepatitis and similar serious maladies. As nothing is more dangerous in microbiology than that which is thought to be safe, any pathological sample appearing at clinical laboratories should be regarded with the suspicion due to a Trojan horse: "Quidquid id est, timeo Danaos et dona ferentes" (Virgil).

We are grateful to Mr. J. Hunter for the photography.

\section{References}

Almeida, J. D., et al. (1971). Lancet, $2,849$.

Altemeier, W. A. (1967). Fournal of the American Medical Association, 202, 111.

Chatigny, M. A. (1961). In Advances in Applied Microbiology, vol. 3, p. 131. ed. W. W. Umbreit, New York, Academic Press.

Chatigny, M. A., and Clinger, D. I. (1969). In An Introduction to Experimental Aerobiology, ed. R. L. Dimmick and A. B. Akers, p. 195. New York, Wiley Interscience.

Darlow, H. M., (1969). In Methods in Microbiology, ed. J. R. Norris and D. W. Ribbons, vol. 1, p. 169, London, Academic Press.

Department of Health and Social Security (1970). Precautions Against Tuberculous Infection in the Diagnostic Laboratory. H.M.(70)60. London, H.M.S.O.

Doxie, F. T., and Ullom, K. J. (1967). Western Electric Engineer, 11, 24.

Evans, C. G. T., Harris-Smith, R., and Stratton, J. E. D. (1972). In Safety in Microbiology. Society for Applied Bacteriology, Technical Series 6. New York, Academic Press. In press.

Griffiths, P. D. (1971). Lancet, 2, 600.

Hartney, J. B. (1970). Fournal of the American Medical Association, 214, 461. Hawe, B. J., Goldsmith, H. J., and Jones, P. O. (1971). British Medical fournal, 1,540

Line, S. J. (1972). Fournal of Clinical Pathology, 25, 93.

McLellan, D. S., and Canning, D. M. (1971). Gazette of the Institute of Me tical Laboratory Technology, 15, 5.

Phillips, G. B. (1961). Microbiological Safety in U.S. and Foreign Laboratories. Technical Manuscript 35. Frederick, Maryland, U.S. Army Biological Laboratories.

Sulkin, S. E. (1960). Unpublished observations quoted by Chatigny (1961). Tomlinson, A. J. H. (1957). British Medical fournal, 2, 15.

\title{
Metastases and the Normalization of Tumour Blood Vessels by ICRF 159: A New Type of Drug Action
}

\section{A. W. LE SERVE, K. HELLMANN}

British Medical fournal, 1972, 1, 597-601

\section{Summary}

Profound modification of the structure and arrangement of the blood vessels has been shown in tumours after treatment with ICRF 159. $X$-ray angiography, carbon black (Pelikan ink) labelling, and intravital staining with lissamine green were used to demonstrate the changes. Alteration of the morphology of the blood \footnotetext{
Department of Cancer Chemotherapy, Imperial Cancer Research
Fund, London WC2A 3PX

A. W. LE SERVE, B.SC., I.C.R.F. Bursar

K. HELLMAN, D.M., D.PHIL., Head
}

vessels at the edge of a tumour may affect the escape of malignant cells and the rate of blood flow (and thus the concentration of anticancer drugs) through the tumour.

\section{Introduction}

Treatment of the Lewis lung carcinoma (3LL) with ICRF 159 ( ( \pm$)-1,2$-bis(3, 5-dioxopiperazin-1-yl) propane) inhibits the pulmonary metastases resulting from bloodborne dissemination of 3LL cells (Hellmann and Burrage, 1969). The growth rate of the primary implant is, however, not significantly impeded by dosages required to produce this effect.

Histological examination of the possible mechanisms in- 
volved showed that the inhibition brought about by ICRF 159 is probably due to normalization of the developing blood vessels at the invading margins of the primary tumours (Salsbury, Burrage, and Hellmann, 1970). In this region an ill-defined leash of poorly formed vascular sinusoids with frequent areas of haemorrhage is replaced, in treated tumours, by vessels of relatively normal appearance and character.

Such modification of the growth of tumour blood vessel structure appears to be a new type of drug action and one which could be of considerable importance, not only for prevention of metastases but also in the treatment of primary and secondary tumours. It seemed desirable, therefore, to study this "angiometamorphic" effect more closely, particularly by means of $x$-ray angiography.

\section{Materials and Methods}

Lewis Lung Carcinoma (3LL).-Tumours were inoculated subcutaneously into the flanks of inbred C57/B1 female mice weighing between 18 and 22 g. Aseptic precautions were observed. Experimental mice received ICRF $15930 \mathrm{mg} / \mathrm{kg}$ suspended in $0.2 \mathrm{ml}$ of carboxymethyl cellulose $(0.5 \%)$ in isotonic saline (CMC) given daily intraperitoneally. Control mice received $0.2 \mathrm{ml}$ of $\mathrm{CMC}$ alone intraperitoneally daily.

Walker 256 Carcinosarcoma.-In order to see differences in tumour vascular pattern more clearly the rat Walker tumour grown in the flanks of Sprague-Dawley rats $(150-200 \mathrm{~g})$ was studied. Experimental rats received ICRF $15950 \mathrm{mg} / \mathrm{kg}$ suspended in $0.4 \mathrm{ml}$ of $\mathrm{CMC}$ solution given intraperitoneally daily. Controls received $0.4 \mathrm{ml}$ of CMC alone.

\section{Radiographic Procedure}

Ninety-two C57/B1 mice with 3LL tumours were used for angiographic studies, of which 67 angiograms were of sufficiently high standard to be used for evaluation. Twenty SpragueDawley rats with Walker tumours were also used, of which 16 angiograms were of a sufficiently high standard.

Various methods for the injection of contrast media into bromethol (Avertin) anaesthetized animals were tried, but retrograde intravenous injection proved most effective. Micropaque (aqueous barium sulphate about $1 \mathrm{oz} / \mathrm{fl}$. oz $(55 \mathrm{~g} / 50 \mathrm{ml})$ ) was injected through a polyethylene catheter introduced into the inferior vena cava through the exposed right heart (Margulis, Carlsson, and McAlister, 1961).

Animals were placed in the supine position on a transparent tray with the $x$-ray tube 18 in $(46 \mathrm{~cm})$ above. $X$-ray film was placed on a shelf 18 in $(46 \mathrm{~cm})$ below and each radiograph was therefore twice life-size. Focal spot of the $x$-ray tube was $0.3 \mathrm{~mm}$ (Parish, Akester, and Gregg, 1964). Care was taken to give the contrast medium in the same volume and identical manner each time.

\section{IN VIVO BLOOD VESSEL LABELLING}

Sixty-four C57/B1 mice with 3LL tumours and 18 rats with Walker tumours were used in these experiments. A colloidal suspension of carbon black (Pelikan biological ink C11/1431a) diluted $1: 4$ with $1 \%$ gelatin in sterile saline was used (Oswald and Cater, 1969). This suspension contains about $10 \mathrm{mg}$ of carbon per ml with an average particle size of $200 \AA$; it is stabilized with $4.5 \%$ fish glue and contains $1.3 \%$ phenol as a preservative.

Mice (C57/B1) inoculated with 3LL tumour and treated with ICRF 159 or CMC received $0.12 \mathrm{ml}$ of the diluted ink per $20 \mathrm{~g}$ mouse into the lateral tail vein; $0.75 \mathrm{ml}$ per $150 \mathrm{~g}$ SpragueDawley rat of the diluted ink was similarly injected intravenously into rats inoculated with the Walker carcinosarcoma treated with ICRF 159 or CMC. The animals were left for one hour and then killed, the tumour and surrounding tissue were quickly removed, placed in $10 \%$ formol saline for 14 days, and then washed in distilled water for 24 hours before being transferred to $12.5 \%$ gelatin at $37^{\circ} \mathrm{C}$ for 24 hours and then for another 24 hours into $25 \%$ gelatin also at $37^{\circ} \mathrm{C}$. The blocks were embedded in $25 \%$ gelatin and stored in formol saline. Frozen sections cut at $25-35 \mu \mathrm{m}$ were lightly stained with alum carmine and mounted in Highman's mountant. At least eight frozen sections cut randomly from each tumour were examined. Random areas of the 3LL primary tumours were examined with the electron microscope in order to locate the position of the ink within the blood vessels.

The tissues were fixed in $4 \%$ glutaraldehyde in phosphate buffer for one hour and then post-fixed for a further hour in phosphate buffered osmic acid, and embedded in Araldite.

Sections (about $400 \AA$ ) were cut on a Porter-Blum microtome equipped with a glass knife and stained with $25 \%$ uranyl acetate in methanol for 10 minutes, washed in methanol, and then further stained in lead citrate for four minutes and washed in distilled water. Sections were lightly coated with carbon and examined in the Siemens Elmiskop 1 electron microscope.

Some 3LL tumours were excised five minutes after intravenous injections of ink, and thick cryostat sections, stained with neutral red, were examined.

\section{INTRAVITAL STAINING WITH LISSAMINE GREEN}

Thirty-six C57/B1 mice inoculated with 3LL tumour and treated with ICRF 159 or CMC received $0.5-1 \mathrm{ml}$ of a $2 \%$ lissamine green solution (Gurr) rapidly into the tail vein (Goldacre and Sylvén, 1962). Five millilitres of 2\% lissamine green solution was similarly injected into rats inoculated with the Walker carcinosarcoma and treated with ICRF 159 or CMC. The animals were exsanguinated under ether five minutes after the injections of lissamine green. The tumours were bisected and examined.

\section{Results}

\section{ANGIOGRAPHY}

\section{LL Tumour}

Host Vessels.-No new vessels were seen to develop in response to the tumour, but host vessels draining the tumour were constantly dilated and some of these vessels became very

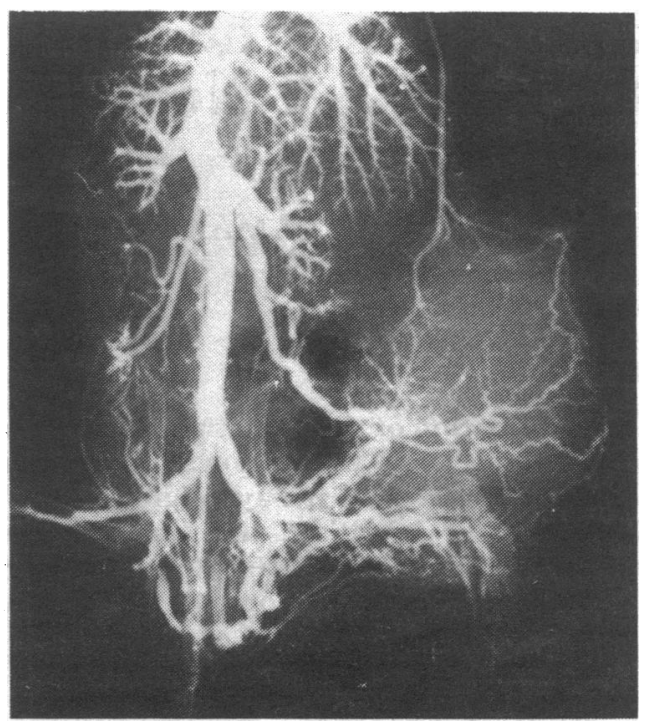

FIG. 1-Venogram of a primary 3LL tumour 14 days after implantation and treated with CMC only. $(x$ 1.4.) 
tortuous. Identical appearances were seen in animals where the tumour was treated with ICRF 159. At the border of the tumour angiographic appearances became very indistinct owing to vascular proliferation. It was not possible to distinguish whether this proliferation was in the host or the tumour tissues. Again the angiographic picture was the same for both control and treated tumours.

Tumour Vessels.-Control tumours showed large filling defects whose size and position varied from tumour to tumour. Such vascularization as there was appeared to be randomly arranged with vessels often ending abruptly (Fig. 1). This proved to be the constant picture in the control tumours. When the tumour was cut Micropaque flowed out from the cut surfaces. Tumours of the treated mice, however, showed numerous discrete blood vessels with some indication of a regular vascular arrangement (Fig. 2).

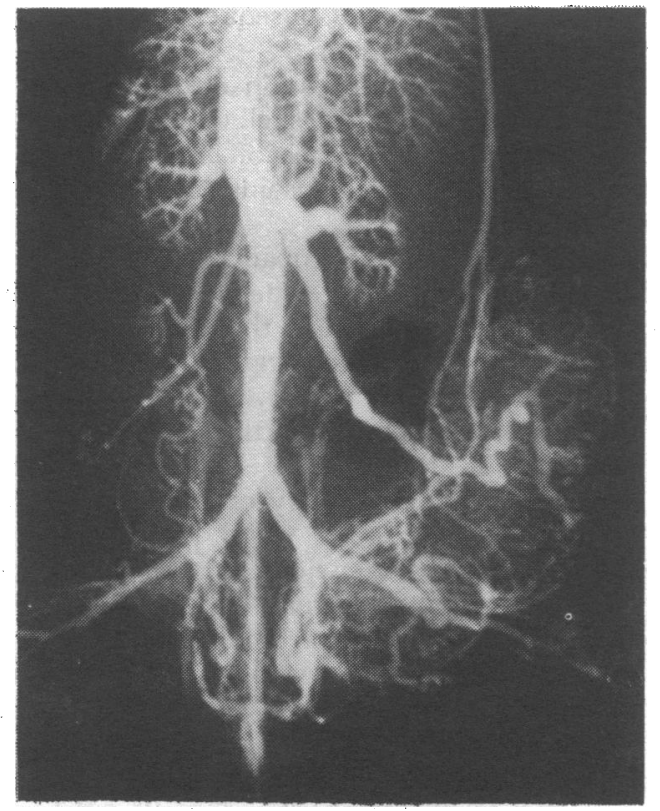

FIG. 2-Venogram of a primary 3LL tumour 14 days after implantation and treated with ICRF 159

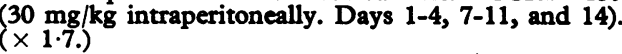

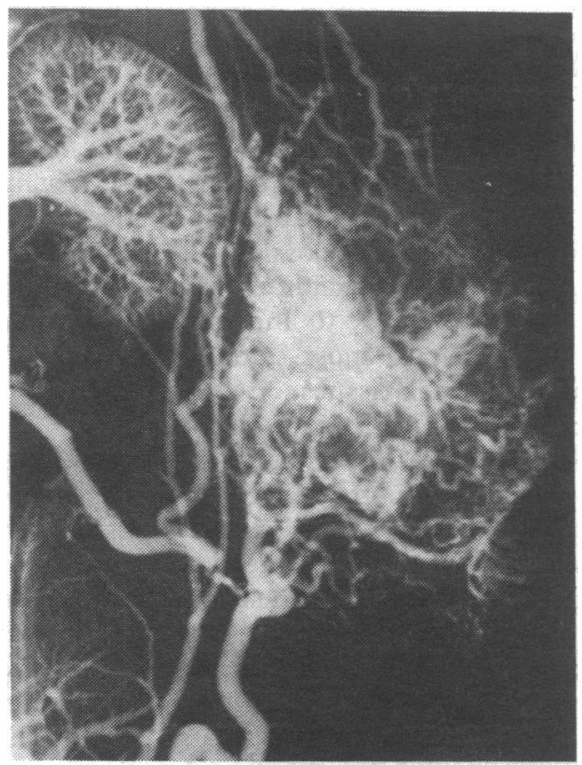

FIG. 3-Venogram of a Walker carcinosarcoma seven days after implantation and treated daily with CMC. $(\times 1.5$.

\section{Walker Tumour}

Host Vessels.-Large new vessels did not develop in response to the tumour. On the other hand, three main host vessels-the lateral thoracic-cutaneous, the ilio-lumbar, and the inferior epigastric veins-were always considerably dilated, presumably to meet the demands of outflow from the tumour. Essentially the same picture was seen in ICRF 159 treated and control tumours. At the margins of the tumour, however, there was considerable proliferation of blood vessels in both treated and control tumours.

Tumour Vessels. - In the tumours themselves there was again a marked contrast between treated and controls. The control tumours showed signs of pooling of the Micropaque; there were avascular areas of varying size and position and commonly "corkscrewing" of dilated vessels. The vessels were also randomly arranged and irregular, all of which is characteristic of tumour blood vessels (Fig. 3). The treated tumours, however, showed no signs of pooling and the blood vessels presented a more orderly arrangement. There was little evidence of any corkscrewing (Fig. 4).

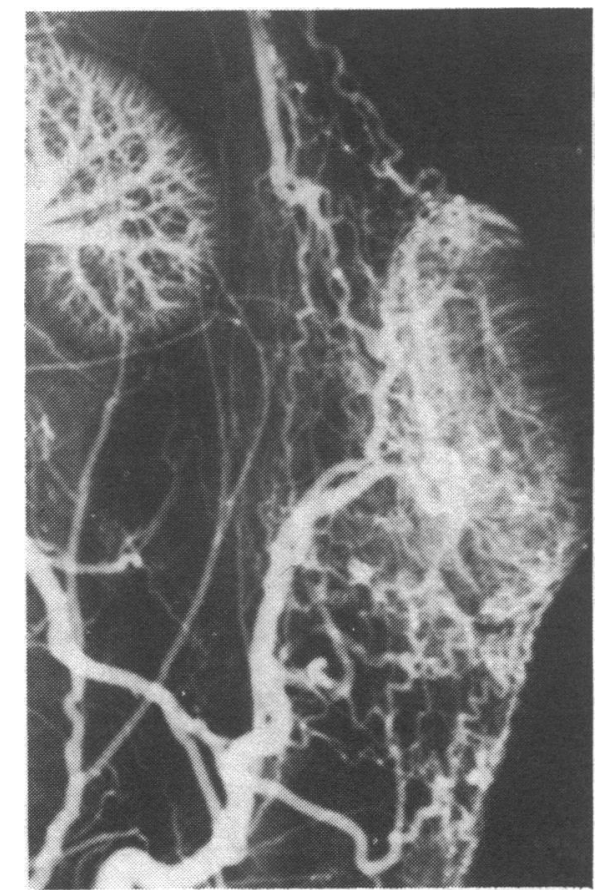

FIG. 4-Venogram of a Walker carcinosarcoms seven days after implantation and treated daily with ICRF $159(50 \mathrm{mg} / \mathrm{kg}$ intraperitoneally). $(\times 1.5$.)

\section{BLOOD VESSEL LABELLING}

\section{LL Tumour}

In thick frozen sections of the primary treated tumours the ink was largely cleared, thus showing little labelling (Fig. 5), but in control tumours many vessels were clearly outlined (Fig. 6). With older and therefore more necrotic tumours the differences between the groups became much less apparent. Electron micrographs of control tumours showed the carbon trapped between basement membrane and an abnormal endothelium.

\section{Walker Tumour}

With this tumour treatment with ICRF 159 also reduced, but by no means abolished, the number of labelled vessels. Labelling in the treated tumours was found only near areas of haemorrhage and necrosis. 


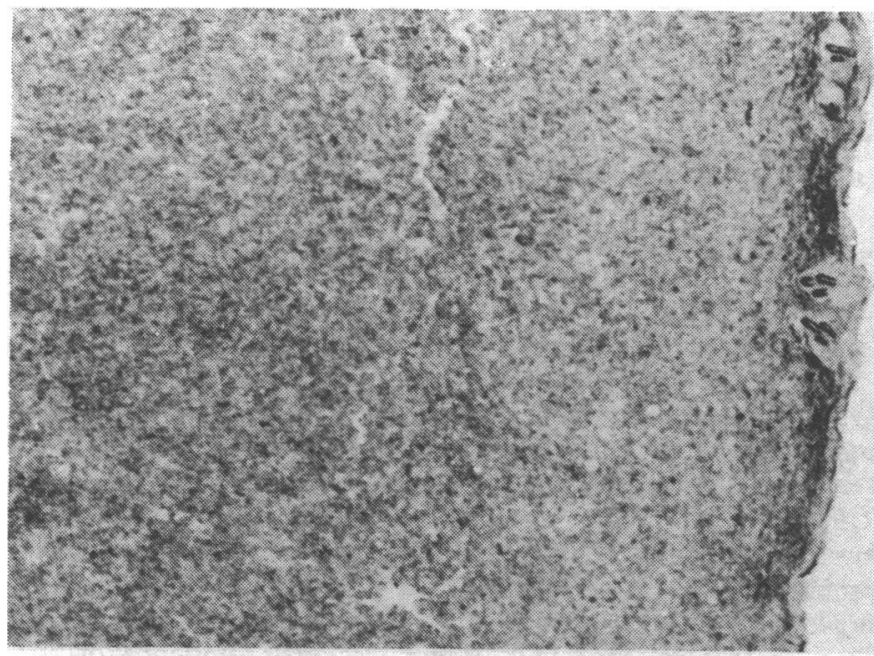

HG. 5-Frozen section of a primary 3LL tumour 14 days after implantation and treated with ICRF 159 (30 mg/kg intraperitoneally. Days 1-4, 7-11, and 14). Tumour excised

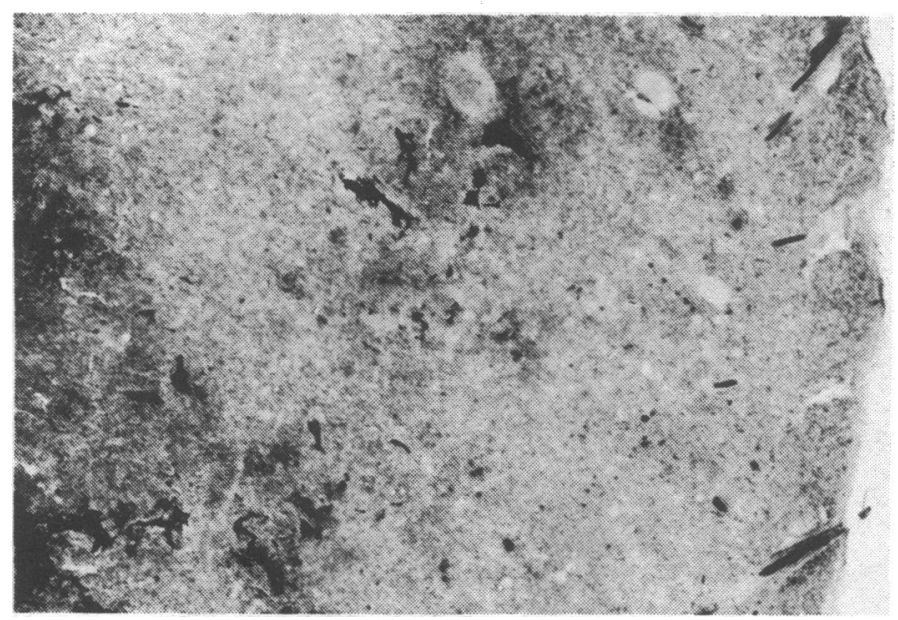

FIG. 6-Frozen section of a primary 3LL tumour 14 days after implantation and treated with carboxymethyl cellulose. Tumour excised one hour after intravenous injection of Pelikan ink. (Alum carmine. $\times 29$.)

\section{INTRAVITAL STANING}

\section{$3 L L$ Tumour}

Gross observations revealed no differences between control and treated tumours at similar ages after tumour implantation. As the tumour increased in size the peripheral non-ischaemic zone became markedly reduced. There were no avascular, colourless areas in the tumour periphery. The youngest tumours (seven days, about $0.8 \mathrm{~cm}$ across) were usually coloured throughout, whereas in the oldest tumours (21 days, about $2.0 \mathrm{~cm}$ across) the peripheral vascularized zone was only a few millimetres thick.

\section{Walker Tumour}

Again gross observations revealed no differences between control and treated tumours. In Walker tumours ranging from $\mathbf{4}$ to $\mathbf{1 0}$ days old there was an increase in the size of the necrotic centre until in the largest tumours only a very thin peripheral vascularized zone remained.

\section{Discussion}

Willis (1952) pointed out that "the structure of the newformed blood vessels in malignant tumours rarely approaches that of normal veins or arteries, and the more rapidly growing the tumour, the more imperfect is the architecture of its vessels ... in highly anaplastic growths, carcinomas as well as sarcomas, even the endothelium may be incomplete in places and the vascular channels lined in part by tumour cells." Clearly such imperfections of vascular structure must favour dissemination of malignant cells. Willis's statement applies with equal force to the Lewis lung carcinoma of the mouse (Salsbury et al., 1970).

Previous observations indicated, however, that the structurally imperfect vascular architecture of the 3LL tumour can be improved by treatment with ICRF 159 (Salsbury et al., 1970) and the present results lend considerable support to the assumption that treatment with this drug normalizes.3LL vasculature functionally as well as morphologically. They also strengthen the conclusion that treatment with ICRF 159 prevents pulmonary metastases because malignant cells do not line, nor do they penetrate, the normalized blood vessels and therefore cannot reach the blood stream. Consequently, they are unable to escape from the primary tumour.

Although it seems clear that as in other tumours the 3LL and the Walker have an outer shell of rapidly proliferating tumour cells permeated by a leash of imperfectly formed and randomly arranged vascular sinusoids, certain aspects of the angiograms call for comment.

In 3LL control tumours Micropaque diffuses into the wide spaces of the sinusoids in a "river-delta" effect, but because of the limitations of the resolution of the $x$-ray technique, radioopaque material cannot be demonstrated. The filling defects are therefore more apparent than real, and if the tumours are bisected Micropaque flows out from the cut surfaces. In treated tumours, however, the Micropaque is confined to the discrete vascular channels and consequently can be seen on the angiograms.

In Pelikan ink studies also, where tumours were excised five minutes after intravenous injection, the ink distributed itself throughout extravascular and intravascular spaces in the controls, but remained confined to the vessels in the treated tumours. The lissamine green injections provide further confirmation that the filling defects in the control venograms reflect only the insufficiently fine resolution of the angiograms.

The lissamine green injections also show that in both treated and control tumours vascularization is confined to an outer zone or cortex which encapsulates the tumours, but that the larger central and probably necrotic medulla appears not to be reached by the dye. It can be assumed, therefore, that Micropaque is also confined to the peripheral zone and that the vessels seen on the angiograms are in the cortex. It seems probable that the blood flow rate in the wide diffuse spaces of the sinusoids in the "avascular" areas of the peripheral zone of the controls is very much lower than in the discrete vascular channels of the cortex of the treated tumours.

Recent histological examination of other tumours treated with ICRF 159 have shown that the blood vessel changes are not confined to the 3LL tumour (Salsbury, Burrage, and Hellmann, to be published). It seems possible, therefore, that the drug affects the fundamental biochemical processes by which a tumour organizes a vascular supply to and into itself. These processes could well be similar in most tumours and have little or no parallel among normal tissues, thereby providing a selective target for cancer chemotherapy.

The abnormal character of tumour blood vessels and their functional normalization by ICRF 159 is well shown by the Pelikan ink experiments. When Pelikan biological ink is injected intravenously it passes rapidly through normal vessels, but is trapped between the basement membrane and the endothelium if they are inflamed or otherwise damaged (Cater and Taylor, 1966; Majno, Palade, and Schoefl, 1961). The considerable degree of vascular labelling in the control Walker and 3LL tumours is greatly diminished on treatment, but less so in the rapidly proliferating Walker tumour than in the more slowly growing 3LL. This, bears out Willis's statement that the more rapidly growing the tumour, the more abnormal its vessels. 
Specific alterations of tumour blood vessels could have considerable consequences for the treatment of tumours. The use of vasoactive drugs to impair selectively the blood supply of tumours has been proposed on occasions-for example, Cater, Grigson, and Watkinson (1962) and Dayal and Goldacre (1969) - but the possibility that drugs might be used to alter blood vessel structure so as to prevent the escape of malignant cells from the primary tumours has not, so far as we are aware, been previously entertained or observed. This angiometamorphic effect may, however, also mean that blood flow rates in treated tumours are higher and that consequently the availability of anticancer drugs might be increased. This consideration may, in part, explain the greater effectiveness of other anticancer drugs when used in combination with ICRF 159 (Hellmann and Burrage, 1970; Woodman, Venditti, Schepartz, and Kline, 1971). Although ICRF 159 is the first compound to be shown to exhibit an angiometamorphic effect, it is unlikely to be unique in this respect, indeed other cytostatic bisdioxopiperazines are known to be active (Burrage, Hellmann, and Salsbury, 1970).

The antimetastatic effect of a number of well-known anticancer agents has recently been investigated (Hellmann and Burrage, in preparation) but only cyclophosphamide has been studied in any detail. Cyclophosphamide inhibits 3LL metastasis, though only to an extent proportional to its inhibition of the growth of the primary implant; it seems to have no angiometamorphic effect (Salsbury et al., 1970). 5-Fluorouracil, like ICRF 159, inhibited metastasis without overt effect on the primary implant. Prednisolone, on the other hand, had a pronounced inhibitory effect on the primary, but did not prevent metastasis. Whether these variations of response are related to changes in the tumour vasculature is being studied.
The profound differences in the mode of action of anticancer drugs as exemplified by these results emphasizes once again that selective therapeutic activity among anticancer agents is more likely to be obtained by closer study of their pharmacological activities than by analysis of their non-specific inhibition of cell division.

We are grateful to Drs. D. B. Cater, R. J. Goldacre, and L. J. F. Youlten, for stimulating discussions and helpful advice, and to Miss L. Peachey for the electron microscopy. We are particularly indebted to Messrs. R. Akester and I. Edgar for their help and guidance with the angiography.

\section{References}

Burrage, K., Hellmann, K., and Salsbury, A. J. (1970). British fournal of Pharmacology, 39, 205P.

Cater, D. B., Grigson, C. M. B., and Watkinson, D. A. (1962). Acta Radiologica, 58, 401.

(1966). British fournal of Cancer, 20, 517 Dayal, S. S., and Goldacre, R. J. (1969). British Empire Cancer Campaign for Research, 47th Annual Report, p. 54.

Goldacre, R. J., and Sylvén, B. (1962). British fournal of Cancer, 16, 306.

Hellmann, K., and Burrage, K. (1969). Nature, 224, 273.

Hellmann, K., and Burrage, K. (1970). Proceedings of the Tenth International Cancer Congress, Houston, p. 682

Majno, G., Palade, G. E., and Schoefl, G. I. (1961). fournal of Biophysical and Biochemical Cytology, 11, 607.

Margulis, A. R., Carlsson, E. R., and McAlister, W. H. (1961). Acta Radiologica, 56, 179 .

Oswald, N. T. A., and Cater, D. B. (1969). British fournal of Experimental Pathology, 50, 84.

Parish, W. E., Akester, A. R., and Gregg, D. McC. (1964). International Archives of Allergy and Applied Immunology, 25, 89.

Salsbury, A. J., Burrage, K., and Hellmann, K. (1970). British Medical fournal, 4, 344.

Willis, R. A. (1952). The Spread of Tumours in the Human Body, p. 115. London, Butterworths.

Woodman, R. J., Venditti, J. M., Schepartz, S. A., and Kline, I. (1971) Proceedings of the American Association for Cancer Research, 12, 24.

\section{Colloid Osmotic Pressure in Erythroblastosis Fetalis}

\section{J. DAVID BAUM, DOROTHY HARRIS}

British Medical fournal, 1972, 1, 601-603

\section{Summary}

Measurements were made of total proteins, albumin, and colloid osmotic pressure on cord blood samples from 15 infants with erythroblastosis fetalis (six of whom were hydropic) and from 151 non-rhesus non-hydropic control infants. The erythroblastotic infants had levels of total protein and albumin which fell within the normal range for gestational age, but their colloid osmotic pressures were abnormally low. It seems that low colloid osmotic pressure may provide a reasonable explanation for the occurrence of hydrops fetalis.

\footnotetext{
Neonatal Research Unit, Institute of Child Health, Hammersmith Hospital, London W12 0HS

J. DAVID BAUM, M.B., CH.B., M.R.C.P., D.C.H., Senior Paediatric Registrar DOROTHY HARRIS, F.I.M.L.T., Senior Technician
}

\section{Introduction}

Hydrops fetalis is characterized by anaemia and generalized oedema and is often accompanied by ascites. A large number of fetal conditions have been described with hydrops fetalis (Driscoll, 1966; Thumasathit et al., 1968). The condition most commonly showing this feature is erythroblastosis fetalis (Gordon, 1972).

Many theories have been offered regarding the pathophysiology of hydrops fetalis (Macafee et al., 1970; Gordon, 1972): profound anaemia leading to intrauterine heart failure; capillary anoxia leading to leakage of protein out of the vascular compartment; the liver, distended with haemopoietic tissue, exerting back pressure on the portal or umbilical veins leading to ascites or placental oedema; and liver dysfunction or loss of protein into the amniotic fluid leading to hypoproteinaemia.

We have examined the possibility that the plasma proteins are disordered in erythroblastosis fetalis, by measuring the total protein concentration, the albumin concentration, and the colloid osmotic pressure in cord blood samples from a group of infants affected by rhesus isoimmunization.

\section{Method}

Lengths of umbilical cord were double-clamped at birth, and venous blood was withdrawn into lithium heparin bottles which were then sealed. The samples were spun at 10,000 r.p.m. for 10 minutes, and the plasma was separated and stored at $-20^{\circ} \mathrm{C}$. At the time of measurement the samples were allowed to warm 